\title{
Regional determinants of economic resilience
}

\author{
Paolo Di Caro' ${ }^{1,2}$. Ugo Fratesi ${ }^{3}$
}

Received: 15 November 2017 / Accepted: 23 November 2017 / Published online: 30 November 2017 (C) Springer-Verlag GmbH Germany, part of Springer Nature 2017

\begin{abstract}
The economic resilience approach recently spread among regional scientists and economic geographers has provided new challenges to empirical researchers interested in studying the overall temporary and persistent consequences of the recent crisis and, more broadly, economic shocks. One of the open issues in this literature is the identification of the determinants of resilience, that is, the factors that influence the evolutionary dynamic process of robustness and adaptability registered in particular places. The selected sample of papers in this special issue provides original contributions for answering the question about what determines regional economic resilience. The common findings of the contributions can be seen as quite robust by relying upon different measures of resilience, cases, methodologies and time periods. Three main conclusions arise from the special issue: most of the determinants of economic resilience show regularities across time and space. The factors that contribute to explain the economic performance of places in normal times are also useful for understanding the patterns observed during and after recessionary events. Policymakers can play an active role in sustaining resilient economies by addressing resources and efforts in the right policy areas without waiting for crises.
\end{abstract}

Some of the contributions in this special issue were presented at the RSA Annual Conference 2015 in Piacenza.

$\bowtie \quad$ Paolo Di Caro

pdicaro@unict.it

Ugo Fratesi

ugo.fratesi@polimi.it

1 Department of Finance, Italian Ministry of Economy and Finance, Rome, Italy

2 Portsmouth Business School, University of Portsmouth, Portsmouth, UK

3 Department of Architecture, Built Environment and Construction Engineering, Politecnico di Milano, Piazza Leonardo da Vinci 32, 20133 Milano, Italy 


\section{Introduction}

The increasing popularity of the concept of resilience in the public debate and among researchers can be justified by two main reasons. First, the Great Recession and its uneven consequences within and across countries posed new challenges to policymaking and, in particular, to the design and the adoption of policies that can help different territories to bounce back from the deep and prolonged crisis and sustain inclusive growth (Lagarde 2017). In this sense, the recent turmoil provided new stimuli to researchers interested in understanding why and where the Great Recession produced the harshest economic and social consequences and how the places more affected by the crisis can undertake recovery paths. Second, the need of interpreting the abrupt and to some extent unexpected effects of the recent crisis motived the search of different conceptual frameworks, which can be able to overcome the weaknesses of standard equilibrium approaches (Boschma 2015). Building on this, the main merit of Ron Martin in his influential seminal paper (Martin 2011) was to use the concept of resilience, which had a well-established tradition in fields like engineering and ecological studies for decades (Holling 1973; Pimm 1984), for reintroducing old concepts in the economic debate such as hysteresis, out-of-equilibrium patterns, and place-specific effects of aggregate shocks.

In few years, the resilience talk experienced a spreading academic success among regional scientists and beyond (Martin 2016): a large number of papers, special issues and books dealing with it have been published. The empirical contributions investigating economic resilience looked at very different realities, from Australia to the USA, many European countries, and some developing nations (Bergeijk et al. 2017). Furthermore, resilience papers focused on different levels of analysis (Modica and Reggiani 2014): country, region, province, city, local labour market, neighbourhood, etc. Also methodologically, the papers were quite different, from case studies (Simmie and Martin 2010; Evans and Karecha 2014) to papers using indicators, shift-share or input-output analysis (e.g. Giannakis and Bruggeman 2017; Martin et al. 2016), to papers using models (e.g. Capello et al. 2015, 2016) to papers using long-run time series to investigate the transition functions of regions (Fingleton et al. 2012; Cellini and Torrisi 2014; Di Caro 2014, 2017). From a policy perspective, the resonance of the concept has also been noteworthy, for instance the European Union highlighted the importance of relying upon the resilience approach for sustaining innovation strategies and inclusive growth in Europe's regions (EU 2017).

\section{The contribution of the special issue}

Despite the notable theoretical and empirical achievements made by scholars studying economic resilience, some unsettled aspects request further investigation (Sensier et al. 2016). In particular, from an empirical and policy point of view, one of the key issues, to which the existing literature provided results that are far from being conclusive, is to understand what explains differences in resilience across countries, regions, cities, and local areas (Martin and Sunley 2015). 
To help filling this gap, this special issue of the Annals of Regional Science contains a selection of applied contributions that aim at providing a better understanding of the determinants of economic resilience. Differences in resilience across places can be due to the combination of several economic, social, and institutional factors on both an aggregate (e.g. country) and disaggregate (e.g. regional) level. By using different measures of economic resilience, methodologies, databanks, time periods and observational units, and focusing on diverse national and international cases, the papers in this special issue represent original steps forward on the path of knowing what makes places more resistant to and able to recover from shocks.

The first three contributions that open this special issue investigate the determinants of economic resilience in the European regions. The work of Fratesi and Perucca explains the asymmetric consequences of the Great Recession in the European NUTS3 regions by underlying the presence of territorial differences in the endowment of structural territorial assets, or "territorial capital", as key factors. In particular, the authors argue that places endowed with material and immaterial capital assets perform better in times of crisis by showing higher degree of resilience in the presence of shocks, and that places with quantitatively similar but qualitatively different territorial capital deal with the crisis in different ways. Bristow and Healy in their contribution provide supporting evidence on the idea that, in the European regions (NUTS-1 and NUTS-2 levels), the capacity for innovation is a crucial element for understanding the different performance of regional labour markets during the Great Recession. More precisely, they distinguish the European regions on the basis of three dimensions of innovation that are operationalised through different indicators: enablers of innovation, innovation activity and innovation outputs and find that innovation leaders either better resisted the crisis or came out of it more rapidly. The contribution of Rizzi, Graziano and Dallara provides an exploratory analysis of the drivers of potential economic, social and environmental resilience in European NUTS-2 regions. The authors adopt a set of explanatory factors in order to understand what has determined the differences in the potential regional resilience observed across Europe since the early 2000s with a particular emphasis on the recent economic and financial crisis.

The remaining contributions present evidence on selected countries, namely the UK, Spain and Italy, which share the presence of relevant internal socio-economic disparities. These countries, moreover, experienced severe employment losses during the recent crisis that were unevenly distributed across territories. Kitsos and Bishop suggest that the asymmetric performance of local authority districts in the UK during and after the recent crisis can be explained by specific factors such as the initial economic conditions, human capital, age structure, urbanisation, and geographical patterns. Interestingly, the authors also underline that a high degree of resilience is observed in the districts where policymakers are aware of investing economic and other resources in the areas that mostly influence resilience. As for Spain, the paper of Angulo, Mur and Trivez combines different econometric techniques, including spatial approaches, by investigating the economic resilience of Spanish labour markets at provincial (NUTS-3) level up to the end of 2015. One of the authors main findings is to provide novel evidence on the fact that the different performance of Spanish provinces during and after the Great Recession can be traced to sectoral and locational advantages. 
Finally, the last three contributions in this special issue provide original results for the Italian case, which has received particular attention in the resilience literature given the long-established internal disparities present in this country. By using novel time series data on employment for the Italian regions (NUTS-1 level) over the past four decades, the work of Di Caro points out that the evolution of female and manufacturing employment across time and space can be used for explaining differences in regional resilience in Italy. The author suggests that, moreover, such explanations have become particularly important since the early 1990s when some structural transformation occurred in this country. Next, Faggian, Gemmiti, Jaquet and Santini investigate the resistance and the recoverability of Italian local labour systems during the Great Recession. They find that a crucial role in defining economic resilience was played by the industrial structure and population size, as well: medium-size local labour systems specialised in Made in Italy's productions show on average high resistance and recoverability. The contribution of Mazzola, Lo Cascio, Epifanio and Di Giacomo throw further light into the determining effects of resilience by looking at the evolution of GDP, exports and employment in the Italian provinces (NUTS-3 level) over the last decade. The determinants of resilience are different according to the indicator used. In particular, the authors point out the relevance of specific territorial factors like agglomeration economies and territorial capital that contribute to explain the different evolution of provinces in Italy also during the recent recession.

\section{Main findings and policy messages}

It is tangible that the resilience approach has provided a worthwhile contribution to regional economics, economic geography and related studies in the recent years. Now, there is quite agreement among scholars on the need of further understanding the place-specific consequences of economic shocks and the spatial patterns of recoveries at different territorial levels. Of particular importance, especially for policymaking, it is has become the study of the factors that shape resilience in the different places. This is not a trouble-free task for empirical researchers given the presence of methodological challenges that mostly derive from issues related to the identification of correct causality patterns and the selection of the most appropriate explaining variables. The contributions in this special issue provided an useful attempt to improve the knowledge about the determinants of resilience by relying upon a wide spectrum of methodologies and cases.

A large number of findings emerge and are supported in different contexts and papers. First, most of the determinants of economic resilience show regularities across time and space. The various articles show that the determinants for resilience detected in different countries mostly overlap, in particular territorial capital and some of its most well-known aspects such as human capital and agglomeration economies.

The second important evidence arising is that the factors that contribute to understand the economic performance of places in normal times are also useful for explaining the specific patterns observed in given territories during and after shocks. As shown by Fratesi and Rodrìguez-Pose (2016), the most resilient regions in times of crisis turned out to be those which were more competitive before the crisis. The papers of the special 
issue show that the factors of regional competitiveness in ordinary times, innovativeness, human capital, agglomeration economies, etc. are also the main determinants of the ability of regions to resist or react to crises.

The third evidence provided is that the spatial scale for the analysis of resilience needs to be a fine one. Most papers show important differences between regions at Nuts3 level, and when data are available, also a smaller sub-regionals scale in terms of local labour markets shows to be appropriate (e.g. British Local Authority Districts or Italian Local Labour Systems).

Finally, on the basis of the papers of the special issue, it is possible provide an interesting and relieving message for the policy makers. Policy can be impactful, and the policy makers can do important things to prepare their regions to the shocks and support resilient economies. However, these efforts cannot come after a crisis has begun, but need to be sustained over time because policies need to focus in the right directions and address regional resources and efforts to establish less mobile assets in regions.

Policies to prepare regions for competition in ordinary times, such as policies to help establishing agile innovation systems, or policies addressing human capital and the structure of regional territorial capital, are also helpful in preparing regions to confront a crisis when it comes.

\section{References}

Bergeijk PA, Brakman S, Marrewijk C (2017) Heterogeneous economic resilience and the great recession's world trade collapse. Pap Reg Sci 96(1):3-12

Boschma R (2015) Towards an evolutionary perspective on regional resilience. Reg Stud 49(5):733-751

Capello R, Caragliu A, Fratesi U (2015) Spatial heterogeneity in the costs of the economic crisis in Europe: Are cities sources of regional resilience? J Econ Geogr 15(5):951-972

Capello R, Caragliu A, Fratesi U (2016) The costs of the economic crisis: Which scenarios for the european regions? Environ Plan C 34:113-130

Cellini R, Torrisi G (2014) Regional resilience in italy: a very long-run analysis. Reg Stud 48(11):1779-1796

Commission EU (2017) Innovation in Europe's regions: strategies for resilient, inclusive and sustainable growth, communication, vol 376. EU Commission, Brussels

Di Caro P (2014) Recessions, recoveries and regional resilience: evidence on Italy. Camb J Reg Econ Soc $8(2): 273-291$

Di Caro P (2017) Testing and explaining economic resilience with an application to Italian regions. Pap Reg Sci 96(1):93-113

Evans R, Karecha J (2014) Staying on top: Why is Munich so resilient and successful? Eur Plan Stud 22(6):1259-1279

Fingleton B, Garretsen H, Martin R (2012) Recessionary shocks and regional employment: evidence on the resilience of UK regions. J Reg Sci 52(1):109-133

Fratesi U, Rodrìguez-Pose A (2016) The crisis and regional employment in Europe: What role for sheltered economies? Camb J Reg Econ Soc 9(1):33-57

Giannakis E, Bruggeman A (2017) Economic crisis and regional resilience: evidence from Greece. Pap Reg Sci 96(3):451-476

Holling CS (1973) Resilience and stability of ecological systems. Ann Rev Ecol Syst 4(1):1-23

Lagarde C (2017) Building a more resilient and inclusive global economy. IMF, Washington

Martin R (2011) Regional economic resilience, hysteresis and recessionary shocks. J Econ Geogr 12(1):1-32

Martin R (2016) Shocking aspects of regional development: towards an economic geography of resilience. The new Oxford handbook of economic geography. Oxford University Press, Oxford

Martin R, Sunley P (2015) On the notion of regional economic resilience: conceptualization and explanation. J Econ Geogr 15(1):1-42 
Martin R, Sunley P, Gardiner B, Tyler P (2016) How regions react to recessions: resilience and the role of economic structure. Reg Stud 50(4):561-585

Modica D, Reggiani A (2014) Spatial economic resilience: overview and perspectives. Netw Spat Econ $15: 1-23$

Pimm SL (1984) The complexity and stability of ecosystems. Nature 307(5949):321-326

Sensier M, Bristow G, Healy A (2016) Measuring regional economic resilience across Europe: operationalizing a complex concept. Spat Econ Anal 11(2):128-151

Simmie J, Martin R (2010) The economic resilience of regions: towards an evolutionary approach. Camb J Reg Econ Soc 3(1):27-43 